\title{
Influence of dispersion aluminum powder on the burning rate of mixed solid fuel
}

\author{
Nikolay Zolotorev ${ }^{1, *}$, Yana Dubkova $^{1}$, and Aleksey Konovalenko ${ }^{1}$ \\ ${ }^{1}$ National Research Tomsk State University, 634050 Tomsk, Russia
}

\begin{abstract}
In work results of experimental study of influence dispersion of metal powder on burning rate in mixed solid fuel are provided. As metal fuel used additive of aluminum of different type depending on dispersion of powder. The prepared samples of mixed solid fuel were tested in constant volume combustion chamber. The received results of burning rate show that at reduction of dispersion of aluminum powder the burning rate of mixed solid fuel increases.
\end{abstract}

\section{Introduction}

The use of high-energy materials nowadays is important [1]. High-energy materials are now widely used in different areas, in fire-extinguishing systems, orientation of spacecraft, rescue operations etc. [2, 3]. Gas generators which generally represent solid-fuel element which consists of mix components the including fuel and oxidizer.

As is known, the solid-fuel charge of the gas generator has a sufficient amount of oxidizer for combustion in a vacuum. These types of solid fuels are explosive and dangerous during their production, storage and transportation. The danger increases with the size of the charge.

New types of gas generator and engines, operating on metallized mixed high-energy materials, are characterized by a wide range of variation of the regime parameters, for example, the pressure, the relative content of the components, and the metal fuel content and its dispersity. Influence on the main characteristics of the working process must be known in order to achieve a maximum realization of the advantages of metallized mixed high-energy materials. For ensuring increase of power characteristics a combustion catalyst is added to the solid fuel composition or metals powders and their oxides into composition of the mixed solid fuel (MSF) [4]. Preliminary thermodynamic calculation allows defining efficiency of use of metal powders and their oxides entered in composition MSF. However, the thermodynamic analysis does not allow estimating effectiveness influence of dispersion of the entered metal powder. Combustion of metal powder in gas generators turns out to be an extremely complex and multifaceted process.

\footnotetext{
* Corresponding author: nikzolotorev@,mail.ru
} 


\section{Object of research}

Dependence of burning rate of MSF turns on pressure is one of the important characteristics. For definition of influence dispersion of metal powder on the burning rate of MSF series of experiments on measurement of burning rate has been carried out.

The main components of mixed solid fuel used in gas generators for wide application are an oxidizer and an inert combustible-binder. As model samples MSF used mix from inert combustible-binder 15.8 wt. \% butadiene rubber plasticized by transformer oil 20/80, ammonium perchlorate 69.2 wt. \% (fraction less than $50 \mu \mathrm{m}$ and $160-315 \mu \mathrm{m}$ in the ratio $40 / 60$ ) and $15 \mathrm{wt}$ \% of additive of metal fuel was used. For solidification of mix 0.5 wt. $\%$ of hardener of TOH-2 over $100 \mathrm{wt} \%$ were added to it. As metal fuel of the aluminum powder of different dispersion was used [5]. Aluminum is one of the most commonly used metal fuels because of its high oxidation enthalpy, high density, low price and good availability. The use of aluminum powder in samples MSF is promising not only in terms of increasing energy characteristics, but also in terms of reducing the agglomeration on the burning surface of samples, increasing the burning rate, and controlling the exponent in the burning rate law [6].

Table 1. The aluminum powder used in experiments.

\begin{tabular}{|c|c|c|c|c|c|}
\hline Type of aluminum powder & ASD4 & ASD6 & ASD8 & ASD10 & ALEX \\
\hline $\begin{array}{c}\text { Size of particles, } \\
D_{43}, \mu \mathrm{m}\end{array}$ & 10.1 & 6.5 & 2.3 & 1.8 & 0.12 \\
\hline
\end{tabular}

After consecutive mixing of components, the received paste was placed in a mold with the subsequent curing within 24 hours at the room temperature. The studied cylindrical samples of MSF with a diameter of $10 \mathrm{~mm}$ and height of $30 \mathrm{~mm}$ were produced in the laboratory by extrusion pressing. The samples of MSF were sorted out based on mechanical integrity criteria and on density values. The study uses samples differing on density not exceeding $0.02 \mathrm{~g} / \mathrm{cm}^{3}$.

\section{Technique and experimental stand for determination of burning rate}

For determination of burning rate different methods can be used [7]. The most widespread method is chamber of constant pressure. In this method combustion of sample of MSF happens with constant pressure and burning rate is defined by usually contact method at combustion of the sample length. This method of determination dependence of burning rate of MSF on pressure is most exact but is very labor-consuming as for each set pressure it is necessary to conduct several experimental tests.

As method measurement of burning rate of samples MSF the burning method in constant volume combustion chamber has been chosen. Use of constant volume combustion chamber allows to determine in one experiment burning rate with the wide range of pressure and to define change of the of burning rate law for the considered range of pressure. The scheme of experimental stand presented in figure 1 . 


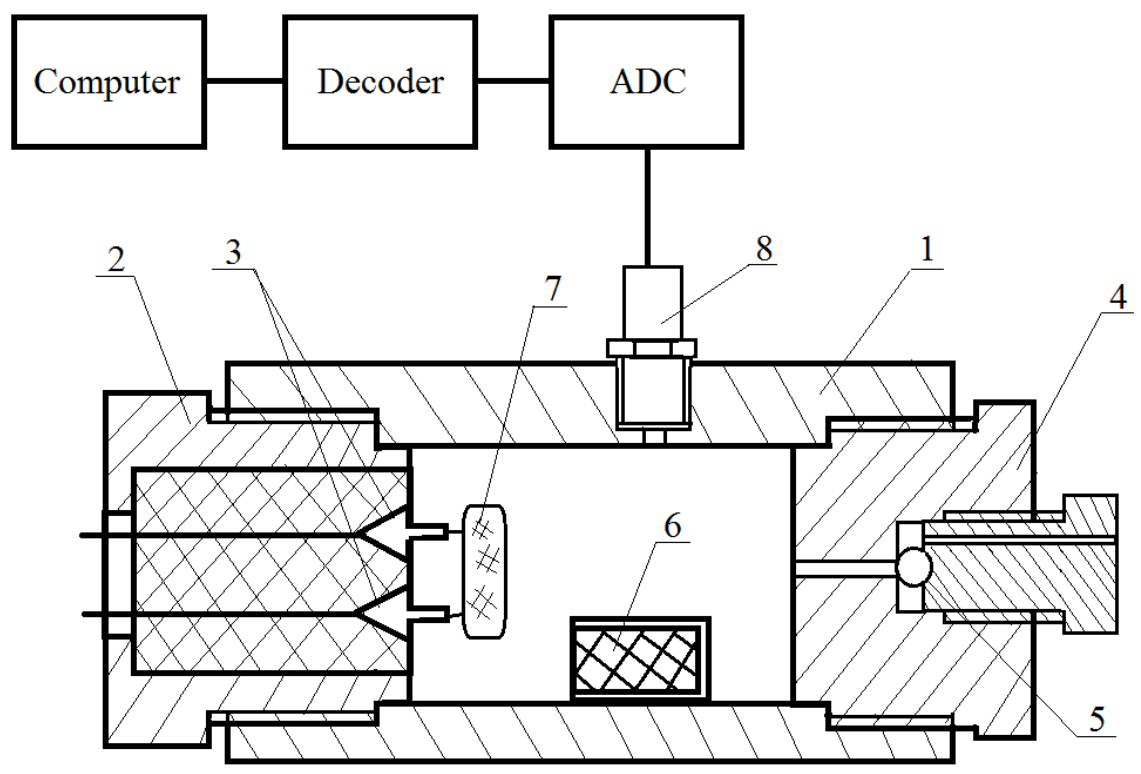

Fig. 1. Scheme of the experimental stand: 1 - chamber casing; 2 - front cover; 3 - insulated wires; 4 - back cover with the pressure release valve; 5 - spherical valve; 6 -MSF sample; 7 -igniter; 8 - pressure sensor.

The volume of constant volume combustion chamber equal to $\mathrm{V}=40 \mathrm{~cm}^{3}$ that at given sizes of MSF sample to provide the rise rate of pressure not less than $10 \mathrm{MPa} / \mathrm{s}$ and maximum pressure is not higher than $30 \mathrm{MPa}$. Measurement of pressure in constant volume combustion chamber was carried out by the pressure sensors tensometric LH-412/400 with use of the digital AT1-8 amplifier and registration of output signal for the computer. The total measurement error does not exceed $1 \%$.

The ignition of sample was carried out using charge of gunpowder weighing $0.1 \mathrm{~g}$. The influenced of gunpowder combustion products on the test sample weighing more than 1 grams can be neglected. Pressure in constant volume combustion chamber does not exceed $30 \mathrm{MPa}$, and temperature of combustion products remains close to MSF sample combustion temperature. Thermal-physical properties of gas can be considered constant and equal to thermal-physical properties combustion products of the sample. Thus, law of conservation of energy and law of conservation of mass for combustion chamber internal volume is written as:

$$
\begin{gathered}
\frac{d m}{d t}=G_{F} \\
\frac{d(m U)}{d t}=G_{F} H_{F}-\frac{d Q}{d t}
\end{gathered}
$$

where $m$ - mass of gas; $G_{F}=\rho_{F} u_{F} S_{F}$ - formation of gas from combustion of a sample; $\rho_{\mathrm{F}}$ - density of the sample MSF; $u_{\mathrm{F}}$ - burning rate of the sample MSF; $S_{\mathrm{F}}$ - burning surface area; $U$ - internal energy of gas; $H_{\mathrm{F}}$ - enthalpy of the sample MSF; $Q$ - the amount of heat expended on heating the chamber casing; $t$ - time.

Using equations (1) and (2), one can obtain expression for burning rate of the sample MSF: 


$$
u_{F}=\frac{V \frac{d p}{d t}+(k-1) \frac{d Q}{d t}}{(k-1) \rho_{F} S_{F} H_{F}-p S_{F}}
$$

where $V$ - combustion chamber internal volume, $k$ - heat capacity ratio for combustion products of the samples MSF.

By the developed technique of determination of burning rate experimental studies of MSF sample combustion have been conducted. The received results of experiments are presented in the form of the degree law of burning rate.

$$
u=u_{0} p^{v}
$$

where $u$ - the burning rate, $u_{0}$ - burning rate at atmospheric pressure $p$ - pressure in the combustion chamber, $v-$ is the exponent in the power-law burning rate.

\section{Results of experimental study}

Investigated model MSF sample comprising ammonium perchlorate, inert combustiblebinder on the basis of rubber SKDM-80 and metal fuel of the aluminum powder of different dispersion was used. In table 2 values of burning rate with atmospheric pressure and exponent in the degree law of burning rate for different type of aluminum powder are provided.

Table 1. Results of experimental study.

\begin{tabular}{|c|c|c|c|c|c|}
\hline Type of aluminum powder & ASD4 & ASD6 & ASD8 & ASD10 & ALEX \\
\hline $\begin{array}{c}\text { Size of particles, } \\
D_{43}, \mu \mathrm{m}\end{array}$ & 10.1 & 6.5 & 2.3 & 1.8 & 0.12 \\
\hline$u_{0}, \mathrm{~mm} / \mathrm{s}$ & 4.0 & 4.8 & 5.3 & 5.1 & 5.2 \\
\hline Exponent $v$ & 0.183 & 0.13 & 0.1 & 0.16 & 0.16 \\
\hline
\end{tabular}

It is shown that as the particle size of the aluminum powder decreases, the burning rate of MSF increases. For aluminum powder which average diameter of particles equal $D_{43}=1.8 \mu \mathrm{m}$ increase in burning rate in relation to particles size $D_{43}=10.1 \mu \mathrm{m}$ makes about $17 \%$ with pressure of $4.0 \mathrm{MPa}$. Further reduction of diameter of particles aluminum powder to micron $D_{43}=0.12$ in comparison with particles aluminum powder $D_{43}=1.8$ does not lead to significant increase in burning rate and is $2 \%$. Dependences of burning rate on pressure are presented on figure 2 . 


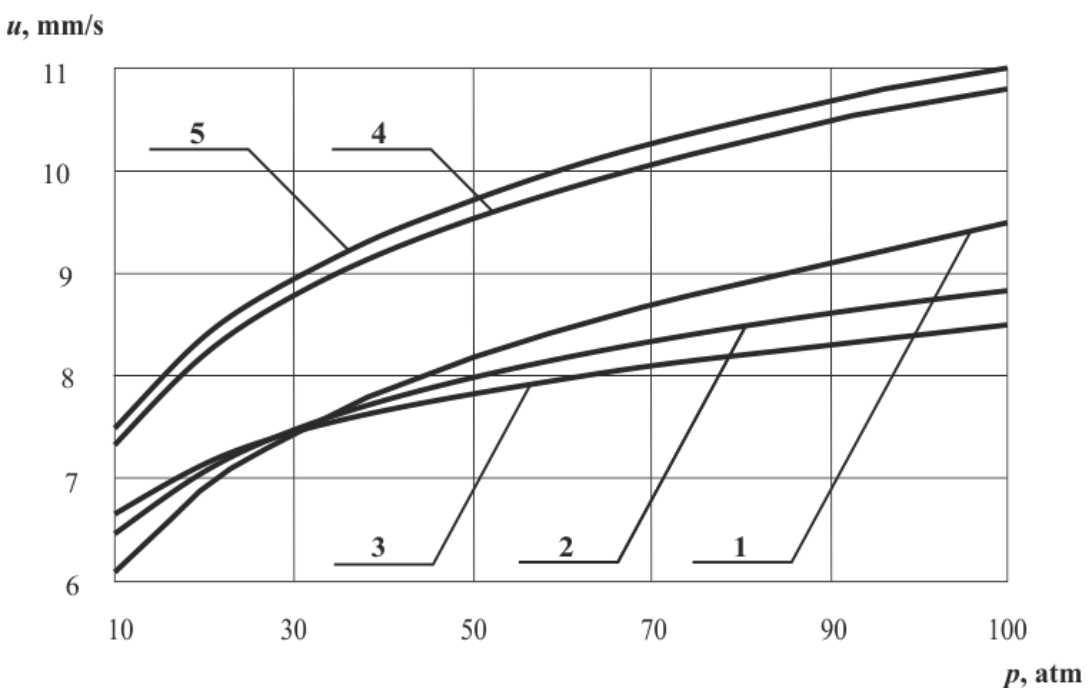

Fig. 2. Dependence of burning rate on pressure: 1 - aluminum powder ASD4, 2 - aluminum powder ASD6, 3 - aluminum powder ASD8, 4 - aluminum powder ASD10, 5 - aluminum powder ALEX.

The experimental results obtained are consistent when compared with known experimental results obtained in chamber of constant pressure. The addition of an aluminum powder of ultrafine size to the composition of the mixed solid fuel allows to increase the density of the samples. The experimental tests carried out in constant volume combustion chamber showed that a reduction of dispersion metal powder used in the composition of fuel (MSF) increases the burning rate of the sample. The burning rate of the mixed solid fuel decreases with increasing particle size of the aluminum powder due to small particle size and small oxide layer thickness, lower temperature of the beginning of rapid oxidation, and the high chemical activity of the Alex ultrafine aluminum powder, which increases the rate of heat transfer into the condensed reaction layer.

Thus, replacement of micro-size aluminum powder by ultra-size aluminum powder can significantly modify the main characteristics of combustion of mixed solid fuels.

This research was supported by The Tomsk State University competitiveness improvement program.

\section{References}

1. P. Pokhil, A. Belyaev, Y. Frolov, Combustion of Powdery Metals in Active Media (Moscow, Nauka, 1972)

2. S. V. Goldaev, N. A. Babushkin, S. A. Basalaev, EPJ Web Conf. 23, 01014 (2015)

3. S. Goldayev, S. Basalayev, N. Minkova, MATEC Web Conf. 72, 01034 (2016)

4. L. T. De Luka, L. Galfetti, F. Severini, Combust. Explos. Shock Waves 41, 680 (2005)

5. V. A. Arkhipov, S. S. Bondarchuk, A. G. Korotkikh, Gorn. Zh., Special Issue: Tsvetn. Met. 4 (2006)

6. V. A. Arkhipov, A. G. Korotkikh, V. T. Kuznetsov, Khimicheskaya Fizika 23, 9 (2004) [In Russian]

7. V. Arkhipov, L. Savel'eva, N. Zolotorev, MATEC Web Conf. 23, 01005 (2015) 